\title{
Coronary Vein
}

National Cancer Institute

\section{Source}

National Cancer Institute. Coronary Vein. NCI Thesaurus. Code C12882.

A blood vessel in the heart which returns coronary blood to the right atrium. 